\title{
Repurposing phenytoin as an anti-aggression drug: clinical evidence
}

\author{
Jan M. Keppel Hesselink* \\ Institute for Neuropathic Pain, Spoorlaan 2a, 3735 MV Bosch en Duin, Netherlands
}

\begin{abstract}
Phenytoin is an anti-epileptic drug that has been evaluated in a clinical setting for 80 years, and results show it has therapeutic potential beyond reduction of seizures. Research has identified neurological, psychiatric and non-CNS indications, such as wound healing, which are supported by pilot studies for phenytoin. Wound healing and aggression are the indications most frequently explored, and preliminary studies with phenytoin demonstrated reduced aggressive outbursts and aggression. We argue that aggression has great potential as an area for phenytoin repurposing, since the unmet need in aggression therapy is very high. Furthermore, especially 'dirty drugs' such as phenytoin, which have promiscuous targets and important physiological relevance seem to hold great promise for repositioning.
\end{abstract}

\section{Drug repurposing and drug repositioning}

Drug repurposing was defined for the first time in 2004 as: "the process of finding new uses outside the scope of the original medical indication for existing drugs is also known as redirecting, repurposing, repositioning, re-tasking and reprofiling" [1]. We would first like to point out that this definition is in need of some adaptation. Repurposing is only possible after a drug has fulfilled its purpose, which occurs after it has received its market authorization for a certain indication from the authorities. This is a prerequisite for any new 'purpose' of the drug. The drug must have been authorized and be available for prescription and use in patients. An example of such repurposing can be seen in amitriptyline, which was first registered as an antidepressant and subsequently 'repurposed' as an analgesic for neuropathic pain. Drugs in the research or development phase cannot be repurposed, but they can be repositioned, re-tasked or re-profiled. Repositioning is therefore the broader, more encompassing concept. Many drugs in the period before registration have been repositioned. Some of those drugs reached the market, after being registered for a new indication, other drugs failed to do so, and the repositioning did not lead to the drug entering the market in a new, different indication to the original one.

The aim of our paper is to add new perspectives to the theoretical body of knowledge of this field. We will focus on an old drug that has been repurposed numerous times, phenytoin, first used as an anticonvulsant in 1937 [2,3]. It is our belief that drugs characterized by 'dirty pharmacology', i.e. based on a promiscuous receptor profile, hold promise for the treatment of many other indications than those for which they were originally approved. Given the increasing failure rates of recent leads, the topic of repositioning needs more attention, as it may revitalize the slowing drug discovery pipeline [4]. We will present the promiscuous target profile of phenytoin and in addition discuss some other profiles of other 'dirty' drugs which are used widely in off-label indications.

It will be mandatory for the field that additional incentives will be developed by governments for non-orphan indications. Drug repurposing has recently been stimulated in universities and by government bodies. Many lists have appeared on putative indications for old drugs. By mentioning a new indication of this type, prior art is created and no-one will ever patent the indication again. So scientists eager to list all putative repurposing indications of old molecules should be aware of this phenomenon, and are advised to analyze the patentability of a new indication prior to publication, because, to date, either an orphan indication, or a patent on formulation or a use patent will create an adequate intellectual property platform for developing such an indication. Without a clear and secured economic incentive, such development will not take place.

To date there is a paucity of repurposing analyses based on previous literature and clinical studies published in the past, and such analysis supports the repositioning of phenytoin as an anti-aggression drug. Old-fashioned closely reading and evaluating papers and data generated in the past, can lead to the recognition of relevant patterns for predicting success for an old drug in a new indication. Importantly, hand in hand with such exploration, we need to evaluate drug and research development shortcomings and limitations of the past, because, in most papers, often only the polished science is reported, and we need to improve our 'reading between the lines', for instance to identify patterns of moving targets [5-8].

In order to analyze the many intricacies of drug repositioning, we used PubMed indexed papers on phenytoin as our working material. We conducted a search, based on the combination of the keyword 'phenytoin', together with the filter 'Clinical Trial'. We excluded all non-randomized studies, as well as all studies of disorders related to convulsions (epilepsy, eclampsia), case collections and/ or studies indexed only because phenytoin was mentioned in the body of the abstract. We selected randomized, controlled studies evaluating phenytoin in clinical indications (e.g. bipolar disorder,

Correspondence to: Jan M Keppel Hesselink, Institute for Neuropathic Pain, Spoorlaan 2a, 3735 MV Bosch en Duin, Netherlands, E-mail: jan@neuropathie.nu

Key words: repositioning, indication, aggression, phenytoin.

Received: September 28, 2017; Accepted: October 18, 2017; Published: October 21,2017 
schizophrenia, pain), or states related to clinical indications (aggression, irritability, anxiety).

\section{Phenytoin: a multi-purpose drug?}

In total, 883 papers were indexed in PubMed, based on the combined keyword search 'phenytoin', together with the filter 'Clinical Trial'. The distribution of the papers is shown in figure 1.

In total, 43 PubMed studies met the selection criteria and are included in this analysis (table 1).

Certainly, the (off-label) indications listed in table 1 support the thesis that phenytoin is a potential multi-purpose drug. Two indications are frequently mentioned: aggression and wound healing. We will explore aggression as an example of phenytoin's repurposing potential, as this is currently an area with high unmet treatment needs. Wound healing will be discussed in a separate paper to be published elsewhere.

\section{Aggression and phenytoin' mechanism of action: a good match?}

As aggression and irritability are symptoms, and symptoms are perhaps more closely linked to a defined pathogenesis compared with syndromes (depression, schizophrenia), we feel we also need to address such a shift from disease or syndrome to symptom clusters when considering drug repurposing. Aggression is an example of this. No drug has been approved yet by the European EMA or U.S. Food and Drug Administration for such use. It might very well be that the pathogenesis of symptoms like aggression and irritability are much more closely linked to biochemical targets than syndromes or indications such as bipolar disorder or schizophrenia. In the case of aggression, we will outline the relevance of especially the sodium channels in the pathogenesis, which is clearly the target of phenytoin.

In 2009, it was pointed out that treatment studies on impulsive aggression using anticonvulsants have supported the role of the sodium channel blockers as well as GABA-related agonists [50]. Conventional anticonvulsants are seen as particularly effective in treating "impulsive aggressive" behavior [51]. Relevant literature characterizing phenytoin's full potential as an ion-channel blocking compound is not easy to find, as most physiological and pharmacological studies of this old compound were conducted in the period before the recognition of the existence of an entire family of sodium channels [3]. There are, however, a number of papers in this field and the data presented in those papers support phenytoin as an unspecific and broad acting sodium channel blocker [3]. This is of great relevance for its putative action as an anti-aggression compound, as phenytoin reduces the amplitude of the sodium dependent action potential through its enhancement of

\section{PubMed search: phenytoin and filter: clinical trial}

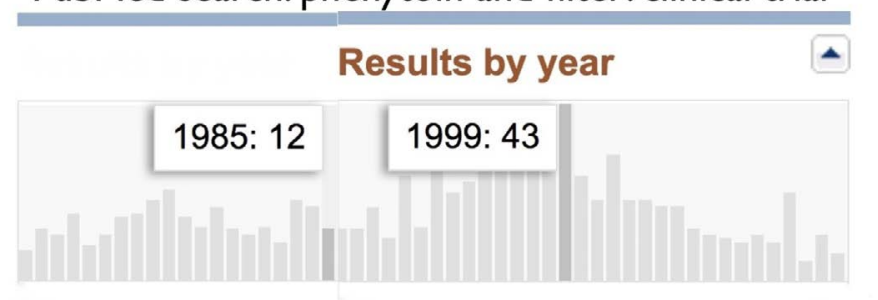

Figure 1. First studies based on the keyword phenytoin and the filter 'clinical trial' were published in 1966 (6 papers); the last study was an RCT on phenytoin in optic neuritis, published in 2016. The years 1985 and 1999 are highlighted as years with low respectively high output of papers, to illustrate the fluctuations in this figure. steady-state inactivation. It is generally accepted that anticonvulsants such as phenytoin might reduce aggression by acting on the central nervous system and reducing neuronal hyper-excitability associated with aggression [52].

In the 1970s, phenytoin was already described as having GABAergic effects [53]. During excited states, such as in neuronal models stimulated via picrotoxin, a $\mathrm{GABA}_{\mathrm{A}}$ antagonist like phenytoin has a strong suppressive effect on the spontaneous hyper-exciting excitatory postsynaptic currents [54]. The responses of neurons to GABA can also be potentiated by phenytoin $[55,56]$. The affinity of phenytoin to the $\mathrm{GABA}_{\mathrm{A}}$ receptor is in the nanomolar range [57]. Furthermore, sodium channels, calcium channels, serotonin and glutamate are often mentioned as factors that play a role in the pathogenesis of aggression [58-61]. Phenytoin has been also documented as inhibiting calcium channels, glutamate release and, acting as an anti-aggressive compound in a low serotonin aggression animal model [62]. Recently elevations of plasma inflammatory markers have been reported in Intermittent Explosive Disorder compared with control [63]. Compounds without anti-inflammatory mechanisms of action, such as fluoxetine nor divalproex tested versus placebo did not influence the aggression [64]. Interestingly, neuro-inflammation is increasingly seen as a pathogenic factor in aggression-lined disorders, such as bipolar disorders [65-66]. Phenytoin seems to inhibit overactive glia and has such anti-inflammatory activity [67]. Phenytoin clearly is a drug with promiscuity for a great number of target: sodium channels and L-type calcium channel, with gaba-ergic and anti-inflammatory activity and especially this may support the repositioning of phenytoin in indications such as aggression and wound-healing. A coherent theory can therefore be conceptualized as to why phenytoin would act as an aggression-inhibitor based on the pathogenesis of aggression and the mechanisms of action of phenytoin. This would lead to more clarity than the usual relationship sought between aggression as a part of a disease entity and the mechanism of action of the drug (Outstanding Questions).

\section{Dirty drugs: drugs with enriched pharmacology for re- positioning}

There are two main factors contributing to increasing the chances for drugs to be repositioned: the drug's pharmacological profile at the receptor level and the impact of the excitated or inhibited biological system by the drug on key physiological functions. Of course the influence of both factors on the pathogenesis of diseases is not always easy to dissect. Phenytoin was identified by a lay person, the Wall street icon Jack Dreyfus (1913-2009), as a multipurpose drug after he successfully used the drug in the late 50s of last century for the treatment of depression. In the section above we discussed its 'dirty' pharmacological profile, influencing a great number of ionchannels (various sodium and calcium channels), the gabaergic and glutaminergic systems and inflammation pathways. It is clear that the many off-label indications for phenytoin, as listed in table 1, cannot be explained by one mechanism only, for instance its blocking effect of the NaV 1.7 sodium channel. The fact that phenytoin influences a number of physiological systems via its promiscuous profile explains its tentative efficacy in a great variety of indications, from aggression and bipolar disorders to wound healing. There are many examples of promiscuous compounds with a very broad activity profile. Palmitoylethanolamide is an autacoid with high affinity for the PPARalpha receptor, and influencing many down-stream targets [68]. This compound was initially positioned as flu prophylaxis and treatment (in the 70 s of last century), later as a mast-cell inhibitor (since the 90s), 
Table 1. All clinical trials of phenytoin in non-convulsion indications that comply with the inclusion criteria.

\begin{tabular}{|c|c|c|c|}
\hline Indication & Year & Design & $\mathbf{N}=$ \\
\hline Optic neuritis [9] & 2016 & RCT, placebo & 86 \\
\hline Mucositis [10] & 2015 & RCT, placebo & 16 \\
\hline Wound healing [11] & 2015 & $\mathrm{RCT}$, comparator & 60 \\
\hline Memory impairment [12] & 2013 & RCT, placebo, crossover & 17 \\
\hline Wound healing [13] & 2011 & RCT, placebo & 65 \\
\hline Vitiligo [14] & 2011 & RCT, placebo & 20 \\
\hline Wound healing [15] & 2007 & RCT, placebo & 28 \\
\hline Depression [16] & 2006 & RCT, placebo & 25 \\
\hline Depression [17] & 2005 & $\mathrm{RCT}$, comparator & 33 \\
\hline Aggression [18] & 2005 & RCT, placebo & 29 \\
\hline Wound healing [19] & 2004 & RCT, placebo & 45 \\
\hline Wound healing [20] & 2004 & RCT, placebo, comparator & 172 \\
\hline Bipolar disorder [21] & 2003 & RCT, crossover & 23 \\
\hline Wound healing [22] & 2003 & $\mathrm{RCT}$, comparator & 102 \\
\hline Wound healing [23] & 2001 & RCT, placebo & 57 \\
\hline Impulsivity [24] & 2001 & RCT, placebo & 46 \\
\hline Bipolar disorder [25] & 2000 & RCT, placebo & 39 \\
\hline Pain $[26]$ & 1998 & RCT, placebo & 12 \\
\hline Aggression [27] & 1997 & RCT, placebo, crossover & 60 \\
\hline Cocaine abuse [28] & 1996 & RCT, placebo & 44 \\
\hline Cholesterol [29] & 1995 & RCT, placebo & 41 \\
\hline Rheumatoid arthritis [30] & 1995 & RCT, placebo & 130 \\
\hline Dystrophic epidermolysis bullosa [31] & 1992 & RCT, placebo, crossover & 22 \\
\hline Cholesterol [32] & 1992 & RCT, placebo & 35 \\
\hline Suxamethonium-induced myalgia [33] & 1992 & RCT, comparator & 60 \\
\hline Cancer pain $[34]$ & 1992 & $\mathrm{RCT}$, comparator & 75 \\
\hline Aggression [35] & 1991 & RCT, crossover & 19 \\
\hline Motion sickness [36] & 1990 & RCT, crossover & 7 \\
\hline Enuresis nocturna [37] & 1989 & RCT & 100 \\
\hline IBS $[38]$ & 1983 & RCT, crossover & $?$ \\
\hline Mountain sickness [39] & 1986 & RCT, placebo & 21 \\
\hline Diabetic neuropathy [40] & 1978 & $\mathrm{RCT}$ & $?$ \\
\hline Diabetic neuropathy [41] & 1977 & RCT, placebo & 10 \\
\hline Arrhythmia [32] & 1975 & $\mathrm{RCT}$, comparator & 81 \\
\hline Binge eating [43] & 1975 & RCT, placebo & 20 \\
\hline Angina pectoris [44] & 1974 & RCT, crossover, placebo & 16 \\
\hline Schizophrenia [45] & 1974 & RCT, placebo & 66 \\
\hline Anxiety, hostility [46] & 1973 & RCT, placebo & 42 \\
\hline IBS [47] & 1973 & $\mathrm{RCT}$, crossover & 14 \\
\hline Psychoneurotism [48] & 1972 & $\mathrm{RCT}$, comparator & 80 \\
\hline Anxiety, anger, irritability [49] & 1970 & RCT, crossover & 15 \\
\hline
\end{tabular}

but has been found to be effective in many chronic pain states, such as neuropathic pain, menstrual pain and central neuropathic pain in multiple sclerosis, in chronic dermatitis and glaucoma. It has also found to be effective in a great variety of models: Alzheimer, Parkinson, depression, anxiety, renal inflammation, inflammatory bowel disorders and pelvic syndrome. [68] This is the reason why the molecule has been characterized as a 'promiscuous' anti-inflammatory and analgesic molecule'. [69]

In figure 2 the two principles are depicted, giving rise to off-label use and defining the drug's repositioning potential.

\section{Phenytoin in clinical trials: proof of its anti-aggressive action?}

Observations related to phenytoin's calming effect on mood, irritability, agitation and aggression can be found in the early history of phenytoin [70-71]. The following studies were all placebo-controlled and randomized but, in all studies, the method of analysis was in the completers only.

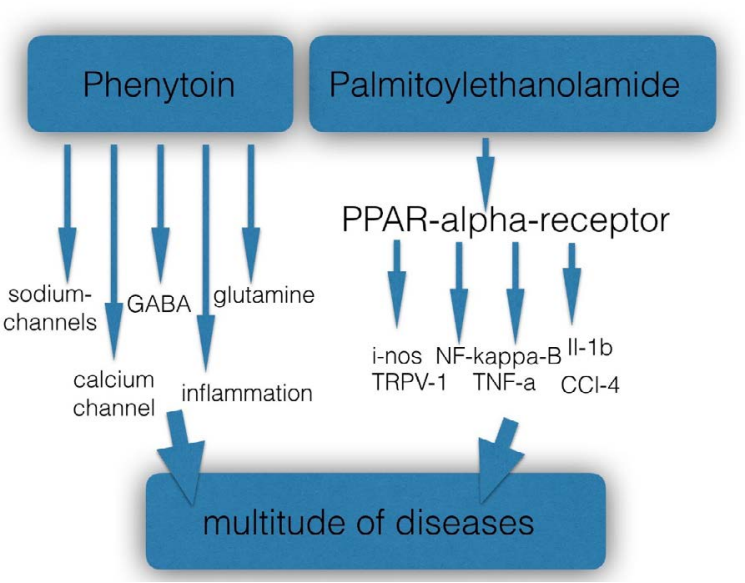

Figure 2. Compounds with a high potential for repositioning are either 'dirty', characterized by enriched pharmacology, such as phenytoin, or influence a key physiological system, such as the autacoid palmitoylethanolamide. 
Twenty-four violent male patients were included in the first study and sequential analysis was employed in a double-blind discontinuation study, so that all patients could be treated with phenytoin. Results indicated that phenytoin was markedly superior to the placebo reducing aggressive outbursts [72].

In 1991, Barratt et al reported the first dose-finding, randomized, placebo-controlled, crossover design in 13 inmates suffering from impulsive-aggressive behavior [35]. Volunteers were treated with a placebo, $100 \mathrm{mg}$ and $300 \mathrm{mg}$ phenytoin daily for four weeks, with a washout period of one week. Plasma levels during the $100 \mathrm{mg}$ treatment period were around $1.1 \mathrm{microg} / \mathrm{ml}$, and $300 \mathrm{mg}$ phenytoin resulted in a level of $4.7 \mathrm{microg} / \mathrm{ml} .300 \mathrm{mg}$ phenytoin resulted in a significant reduction in the profile of mood state (POMS) scores for tension anxiety and depression-dejection, while it also reduced the frequency of aggressive acts.

In 1997, these findings were replicated in a double-blind, placebocontrolled crossover study in 60 inmates, who were administered $300 \mathrm{mg}$ phenytoin daily or a placebo for six weeks, with a one-week washout period [27]. Aggression was measured using the Overt Aggression Scale (OAS) and via the POMS. Impulsive aggression was significantly reduced by phenytoin. Phenytoin levels of below $4 \mathrm{mg} /$ $\mathrm{ml}$ did not seem to reduce aggression, while a higher level, $5 \mathrm{mg} / \mathrm{ml}$, did (based on frequency and intensity of aggressive acts). A surrogate endpoint, the P300 wave, also normalized under phenytoin treatment, as did tension-anxiety scores of the POMS.

In 2001, Matthew S. Stanford et al published the results of a placebo-controlled, crossover study in which the primary outcome measures were the OAS and the POMS [24]. An analysis was carried out on 23 completers suffering from an axis II disorder and scoring eight or more on the Irritability subscale of the Buss-Durkee Hostility Inventory. Treatment was carried out for six weeks with either a placebo or $100 \mathrm{mg}$ phenytoin t.i.d. Aggressive behavior (outbursts) was reduced from 1.4 /week to 1 with the placebo and 0.6 with phenytoin treatment $(\mathrm{p}<0.1)$.

In 2005, Stanford and colleagues published the results of an eightweek double-blind, randomized, placebo-controlled, parallel groups design in 29 patients in which they compared a placebo to phenytoin, valproate and carbamazepine [51]. The primary efficacy parameter was the OAS. Baseline scores were around 4-5. All anticonvulsants reduced aggression significantly, but phenytoin seemed quicker in the onset of action and had a more consistent response.

In 2006, Houston and Stanford published the results of a 16-week, double-blind, placebo-controlled crossover design in 17 completers who underwent six weeks of treatment with phenytoin $300 \mathrm{mg} /$ day $(100$ mg t.i.d.) or a placebo and a two-week washout phase. Unfortunately, the results were reported in a way that was difficult to understand, completers (17) versus non-completers (11) and responders (7) versus non-responders (10).

In 2011, all studies discussed above were implemented in a metaanalysis [73]. This analysis included all studies in the field evaluating anticonvulsants in aggression; a total of 10 studies were analyzed: four on phenytoin (although Barratt 1991 was not included), two on carbamazepine, two on valproate, one on lithium and one on leviracetam. The overall data supported the use of anticonvulsants in aggression, although the leviracetam study was negative, as was one valproate study. Phenytoin clearly scored the best out of all four anticonvulsants.

\section{Concluding comments and future perspectives}

Drug repositioning and repurposing will increase in importance and become an important inroad to expanding our therapeutic armamentarium. The case of phenytoin demonstrates the value of an old 'dirty' drug in modern times. We have demonstrated a great number of putative off-label indications for phenytoin since its first use in the clinic as an antiepileptic drug in 1937. There is a long tradition of observations and clinical pilot studies in aggression as a symptom, effectively treated by phenytoin. All observations and results of the pilot studies point in the same direction. Phenytoin in a low dose range (50\% of its normal anticonvulsive dose), and supported by subclinical concentrations of phenytoin in the blood, consistently reduced the number of aggressive outbursts and aggressive scores on measurement scales. One meta-analysis and six controlled studies all documented the value and safety of phenytoin for this indication. Scoring scales were used to document aggressive behavior and, as we pointed out in the Outstanding Question Box, classical ethological approaches might lead to greater sensitivity and less variability and should be developed in the $21^{\text {st }}$ century. A key question will be whether those data are reproducible. Professor Ioannidis' group recently published 'A manifesto for reproducible science' [74]. The authors list a number of threats to reproducible science, and some seem to apply to the papers discussed above such as low statistical power, analytical flexibility and data dredging.

Phenytoin has been evaluated in a clinical setting for 80 years and has an impressive track record of drug repurposing, as can be seen in Table 1. Innovations in the field of phenytoin and other old drugs with 'dirty pharmacology and promiscuous receptor profiles' are possible and need to be explored more intensely. As 'dirty' and 'promiscuous' are terms with a negative connotation. It might be recommendable to use instead the term 'drugs with enriched pharmacology'. Such class of drugs might have a great potential for repurposing. It has been a telling story that compounds with enriched pharmacology, such as haloperidol and clozapine have never been surpassed in efficacy by highly selective drugs.

\section{Conflict of interest}

The author is one of the patent holders of two patents related to repurposing of phenytoin: 'Topical phenytoin for use in the treatment of peripheral neuropathic pain' and 'Topical pharmaceutical composition containing phenytoin and a (co-) analgesic for the treatment of chronic pain'.

\section{References}

1. Ashburn TT, Thor KB (2004) Drug repositioning: identifying and developing new uses for existing drugs. Nat Rev Drug Discov 3: 673-683. [Crossref]

2. Putnam TJ, Merritt HH (1937) Experimental determination of the anticonvulsant properties of some phenyl derivatives. Science 85: 525-526. [Crossref]

3. Keppel Hesselink JM, Kopsky DJ (2017) Phenytoin: 80 years young, from epilepsy to breast cancer, a remarkable molecule with multiple modes of action. J Neurol 264 : 1617-1621. [Crossref]

4. Issa NT, Byers SW, Dakshanamurthy S (2013) Drug repurposing: translational pharmacology, chemistry, computers and the clinic. Curr Top Med Chem 13: 2328 2336. [Crossref]

5. Wilkinson GF, Pritchard K (2015) In vitro screening for drug repositioning. J Biomol Screen 20: 167-179. [Crossref]

6. Li J, Zheng S, Chen B, Butte AJ, Swamidass SJ, et al. (2016) A survey of current trends in computational drug repositioning. Brief Bioinform 17: 2-12. [Crossref]

7. Kharkar PS, Warrier S, Gaud RS (2014) Reverse docking: a powerful tool for drug repositioning and drug rescue. Future Med Chem 6: 333-342. [Crossref] 
8. Shameer K, Readhead B, Dudley JT (2015) Computational and experimental advances in drug repositioning for accelerated therapeutic stratification. Curr Top Med Chem 15: 5-20. [Crossref]

9. Raftopoulos R, Hickman SJ, Toosy A, Sharrack B, Mallik S, et al. (2016) Phenytoin for neuroprotection in patients with acute optic neuritis: a randomised, placebo-controlled, phase 2 trial. Lancet Neurol 15: 259-269. [Crossref]

10. Baharvand M, Hamian M1, Moosavizadeh MA, Mortazavi A, Ameri A (2015) Phenytoin mouthwash to treat cancer therapy-induced oral mucositis: A pilot study Primary neuroendocrine carcinoma of breast: A rare tumor. Indian J Cancer 52: 81-85. [Crossref]

11. Panahi Y, Izadi M, Sayyadi N, Rezaee R, Jonaidi-Jafari N, et al. (2015) A comparative trial of Aloe vera/olive oil combination cream versus phenytoin cream in the treatment of chronic wounds. J Wound Care 24: 459-60. [Crossref]

12. Brown E.S, Lu H, Denniston D, Uh J, Thomas BP, et al. (2013) A randomized, placebocontrolled proof-of-concept, crossover trial of phenytoin for hydrocortisone-induced declarative memory changes. J Affect Disord 150: 551-558. [Crossref]

13. Shaw J, Hughes CM, Lagan KM, Stevenson MR, Irwin CR, et al. (2011) The effect of topical phenytoin on healing in diabetic foot ulcers: a randomized controlled trial. Diabet Med 28: 1154-1157. [Crossref]

14. Bahmani M, Fallahzadeh MK, Jowkar F, Khalesi M, Bahri-Najafi R, et al. (2011) Can topical phenytoin augment the therapeutic efficacy of PUVA against vitiligo? A doubleblind, randomized, bilateral-comparison, placebo-controlled study. J Dermatolog Treat 22: 106-108. [Crossref]

15. Subbanna PK, Margaret Shanti FX, George J, Tharion G, Neelakantan N, et al. (2007) Topical phenytoin solution for treating pressure ulcers: a prospective, randomized, double-blind clinical trial. Spinal Cord 45: 739-743. [Crossref]

16. Shapira B, Nemets B, Trachtenberg A, Belmaker RH (2006) Phenytoin as an augmentation for SSRI failures: a small controlled study. J Affect Disord 96: 123-126. [Crossref]

17. Nemets B, Bersudsky Y, Belmaker RH (2005) Controlled double-blind trial of phenytoin vs. fluoxetine in major depressive disorder. J Clin Psychiatry 66: 586-590. [Crossref]

18. Stanford MS, Helfritz LE, Conklin SM, Villemarette-Pittman NR, Greve KW, et al. (2005) A comparison of anticonvulsants in the treatment of impulsive aggression. Exp Clin Psychopharmacol 13: 72-77. [Crossref]

19. Bhatia A (2004) Topical phenytoin suspension and normal saline in the treatment of leprosy trophic ulcers: a randomized, double-blind, comparative study. J Dermatolog Treat 15: 321-327

20. Hollisaz MT, Hossein Khedmat, Fatemeh Yari (2004) A randomized clinical tria comparing hydrocolloid, phenytoin and simple dressings for the treatment of pressure ulcers [ISRCTN33429693]. BMC Dermatol 4: 1-18. [Crossref]

21. Mishory A, Winokur M, Bersudsky Y (2003) Prophylactic effect of phenytoin in bipolar disorder: a controlled study. Bipolar Disord 5: 464-467. [Crossref]

22. Carneiro PM, Nyawawa ET (2003) Topical phenytoin versus EUSOL in the treatment of non-malignant chronic leg ulcers. East Afr Med J 80: 124-129. [Crossref]

23. Pai MR, Sitaraman N, Kotian MS (2001) Topical phenytoin in diabetic ulcers: a double blind controlled trial. Indian J Med Sci 55: 593-599. [Crossref]

24. Stanford MS, Houston RJ, Mathias CW, Greve KW, Villemarette-Pittman NR, et al. (2001) A double-blind placebo-controlled crossover study of phenytoin in individuals with impulsive aggression. Psychiatry Res. 103: 193-203. [Crossref]

25. Mishory A, Yaroslavsky Y, Bersudsky Y, Belmaker RH (2000) Phenytoin as an antimanic anticonvulsant: a controlled study. Am J Psychiatry 157: 463-465. [Crossref]

26. Webb J, Kamali F (1998) Analgesic effects of lamotrigine and phenytoin on coldinduced pain: a crossover placebo-controlled study in healthy volunteers. Pain 76 : 357-363. [Crossref]

27. Barratt ES, Stanford MS, Felthous AR, Kent TA (1997) The effects of phenytoin on impulsive and premeditated aggression: a controlled study. J Clin Psychopharmacol 17: 341-349. [Crossref]

28. Crosby RD, Pearson VL, Eller C, Winegarden T, Graves NL (1996) Phenytoin in the treatment of cocaine abuse: a double-blind study. Clin Pharmacol Ther 59: 458-468. [Crossref]

29. Miller M, Burgan RG, Osterlund L, Segrest JP, Garber DW (1995) A prospective, randomized trial of phenytoin in nonepileptic subjects with reduced HDL cholesterol. Arterioscler Thromb Vasc Biol 15: 2151-2156. [Crossref]
30. Rao UR, Naidu MU, Kumar TR, Shobha U, Askar MA, et al. (1995) Comparison of phenytoin with auranofin and chloroquine in rheumatoid arthritis--a double blind study. J Rheumatol 22: 1235-1240. [Crossref]

31. Caldwell-Brown D, Stern RS, Lin AN, Carter DM (1992) Lack of efficacy of phenytoin in recessive dystrophic epidermolysis bullosa. Epidermolysis Bullosa Study Group. $N$ Engl J Med 327: 163-167. [Crossref]

32. McKenney JM, Petrizzi KS, Briggs GC, Wright JT Jr. (1992) The effect of low-dose phenytoin on high-density lipoprotein cholesterol. Pharmacotherapy 12: 183-188. [Crossref]

33. Hatta V, Saxena A, Kaul HL (1992) Phenytoin reduces suxamethonium-induced myalgia. Anaesthesia 47: 664-667. [Crossref]

34. Yajnik S, Singh GP, Singh G, Kumar M (1992) Phenytoin as a coanalgesic in cancer pain. J Pain Symptom Manage 7: 209-213. [Crossref]

35. Barratt ES, Kent TA, Bryant SG, Felthous AR (1991) A controlled trial of phenytoin in impulsive aggression. J Clin Psychopharmacol 11: 388-389. [Crossref]

36. Chelen W1, Kabrisky M, Hatsell C, Morales R, Fix E, et al. (1990) Use of phenytoin in the prevention of motion sickness. Aviat Space Environ Med 61: 1022-1025. [Crossref]

37. Khosroshahi HE, Bozkurt V, Sadikoğlu N, Atakan C (1989) Treatment of nocturnal enuresis: a placebo-controlled trial with piracetam, diphenylhydantoin and psychotherapy. Turk J Pediatr 31: 215-220. [Crossref]

38. Chadda VS (1983) A double blind crossover study of diphenylhydantoin in irritable bowel syndrome. J Assoc Physicians India 31: 425-427.

39. Wohns RN, Colpitts M, Clement T, Karuza A, Blackett WB, et al. (1986) Phenytoin and acute mountain sickness on Mount Everest. Am J Med 80: 32-36. [Crossref]

40. Chadda VS, Mathur MS (1978) Double blind study of the effects of diphenylhydantoin sodium on diabetic neuropathy. J Assoc Physicians India 26: 403-406. [Crossref]

41. Saudek CD, Werns S, Reidenberg MM (1977) Phenytoin in the treatment of diabetic symmetrical polyneuropathy. Clin Pharmacol Ther 22: 196-199. [Crossref]

42. Karlsson E (1975) Procainamide and phenytoin. Comparative study of their antiarrhythmic effects at apparent therapeutic plasma levels. Br Heart J 37: 731-740. [Crossref]

43. Wermuth BM, Davis KL, Hollister LE, Stunkard AJ (1977) Phenytoin treatment of the binge-eating syndrome. Am J Psychiatry 134: 1249-1253. [Crossref]

44. Taylor CR (1974) Double-blind crossover study of diphenylhydantoin in angina pectoris. Chest 66: 422-427. [Crossref]

45. Simopoulos AM, Pinto A, Uhlenhuth EH, McGee JJ, DeRosa ER (1974) Diphenylhydantoin effectiveness in the treatment of chronic schizophrenics. A doubleblind controlled study with a placebo. Arch Gen Psychiatry 30: 106-111. [Crossref]

46. Gottschalk LA, Covi L, Uliana R, Bates DE (1973) Effects of diphenylhydantoin on anxiety and hostility in institutionalized prisoners. Compr Psychiatry 14: 503-511. [Crossref]

47. Greenbaum DS, Ferguson RK, Kater LA, Kuiper DH, Rosen LW (1973) A controlled therapeutic study of the irritable-bowel syndrome: effect of diphenylhydantoin. $N$ Engl J Med 288: 13-16. [Crossref]

48. Uhlenhuth EH, Stephens JH, Dim BH, Covi L, (1972) Diphenylhydantoin and phenobarbital in the relief of psychoneurotic symptoms. A controlled comparison. Psychopharmacologia 27: 67-84. [Crossref]

49. Stephens JH, Shaffer JW (1970) A controlled study of the effects of diphenylhydantoin on anxiety, irritability, and anger in neurotic outpatients. Psychopharmacologia 17: 169-181. [Crossref]

50. Stanford MS, Anderson NE, Lake SL, Baldridge RM (2009) Pharmacologic treatment of impulsive aggression with antiepileptic drugs. Curr Treat Options Neurol 11: 383 390. [Crossref]

51. Stanford MS, Helfritz LE, Conklin SM, Villemarette-Pittman NR, Greve KW (2005) A Comparison of Anticonvulsants in the Treatment of Impulsive Aggression. Exp Clin Psychopharmacol 13: 72-77. [Crossref]

52. Huband N, Ferriter M, Nathan R, Jones H (2010) Antiepileptics for aggression and associated impulsivity. Cochrane Database Syst Rev CD003499. [Crossref]

53. Deisz RA, Lux HD (1977) Diphenylhydantoin prolongs postsynaptic inhibition and iontophoretic GABA action in the crayfish stretch receptor. Neurosci Lett 5: 199-203. [Crossref]

54. Chou MY1, Lee CY2, Liou HH3, Pan CY4 (2014) Phenytoin attenuates the hyperexciting neurotransmission in cultured embryonic cortical neurons. Neuropharmacology 83: 54-61. [Crossref] 
55. Ayala GF, Lin S, Johnston D (1977) The mechanism of action of diphenylhydantoin or invertebrate neurons. I. Effects on basic membrane properties. Brain Res 121: 245258. [Crossref]

56. Connors BW (1981) A comparison of the effects of pentobarbital and diphenylhydantoin on the GABA sensitivity and excitability of adult sensory ganglion cells. Brain Res 207: 357-369. [Crossref]

57. Granger P, Biton B, Faure C, Vige X, Depoortere H (1995) Modulation of the gammaaminobutyric acid type A receptor by the antiepileptic drugs carbamazepine and phenytoin. Mol Pharmacol 47: 1189-1196. [Crossref]

58. Stanford MS, Anderson NE, Lake SL, Baldridge RM (2009) Pharmacologic treatment of impulsive aggression with antiepileptic drugs. Curr Treat Options Neurol 11: 383390. [Crossref]

59. Kania BF, Dębski B, Wrońska D, Zawadzka E (2015) Verapamil - L type voltage gated calcium channel inhibitor diminishes aggressive behavior in male Siamese fighting fish. Pol J Vet Sci 18: 401-406. [Crossref]

60. Jinnah HA, Yitta S, Drew T, Kim BS, Visser JE, et al. (1999) Calcium channel activation and self-biting in mice. Proc Natl Acad Sci U S A 96: 15228-15232. [Crossref]

61. Takahashi A, Lee RX, Iwasato T, Itohara S, Arima H, et al. (2015) Glutamate input in the dorsal raphe nucleus as a determinant of escalated aggression in male mice. $J$ Neurosci 35: 6452-6463. [Crossref]

62. Keele NB (2001) Phenytoin inhibits isolation-induced aggression specifically in rats with low serotonin. Neuroreport 12: 1107-1112. [Crossref]

63. Coccaro EF, Lee R, Coussons-Read M (2014) Elevated plasma inflammatory markers in individuals with intermittent explosive disorder and correlation with aggression in humans. JAMA Psychiatry 71: 158-165. [Crossref]
64. Coccaro EF, Lee R, Breen EC, Irwin MR (2015) Inflammatory markers and chronic exposure to fluoxetine, divalproex, and placebo in intermittent explosive disorder. Psychiatry Res 229: 844-849. [Crossref]

65. da Silva EG, Pfaffenseller B, Walz J, Stertz L, Fries G, et al. (2017) Peripheral insulinlike growth factor 1 in bipolar disorder. Psychiatry Res 250: 30-34. [Crossref]

66. SayuriYamagata A, Brietzke E, Rosenblat JD, Kakar R, McIntyre RS (2017) Medical comorbidity in bipolar disorder: The link with metabolic-inflammatory systems. $J$ Affect Disord 211: 99-106. [Crossref]

67. Dambach H, Hinkerohe D, Prochnow N, Stienen MN, Moinfar Z (2014) Glia and epilepsy: experimental investigation of antiepileptic drugs in an astroglia/microglia coculture model of inflammation. Epilepsia 55: 184-192. [Crossref]

68. Keppel Hesselink JM (2013) Evolution in pharmacologic thinking around the natura analgesic palmitoylethanolamide: from nonspecific resistance to PPAR-a agonist and effective nutraceutical. J Pain Res 6: 625-634. [Crossref]

69. Keppel Hesselink JM, Ciro Costagliola, Josiane Fakhry, Kopsky DJ (2014) Palmitoylethanolamide (PEA): 'Promiscuous' anti-inflammatory and analgesic molecule at the interface between nutrition and pharma. PharmaNutrition 2: 19-25. [Crossref]

70. Freyhan F (1945) Dilantin in Agitated Depression. Arch. Neurol Psychiat 53: 370-374.

71. Blair D (1939) Treatment of epilepsy with epanutin. The Lancet 234: 363-367.

72. Maletzky BM1, Klotter J (1974) Episodic dyscontrol: a controlled replication. Dis Nerv Syst 35: 175-179. [Crossref]

73. Jones RM, Arlidge J, Gillham R, Reagu S, van den Bree M, et al. (2011) Efficacy of mood stabilisers in the treatment of impulsive or repetitive aggression: systematic review and meta-analysis. Br J Psychiatry 198: 93-98. [Crossref]

74. Munafò MR (2017) A manifesto for reproducible science. Nature Human Behaviour 10: $10-21$.

Copyright: (C2017 Hesselink JMK. This is an open-access article distributed under the terms of the Creative Commons Attribution License, which permits unrestricted use, distribution, and reproduction in any medium, provided the original author and source are credited. 